\title{
Long-term trends in the development of the epidemiology of breast cancer in the Slovak and Czech Republic with reference to applied screening and international comparisons
}

\author{
M. ONDRUSOVA ${ }^{1,2 *}$, J. MUZIK 3 , S. DURDIK ${ }^{4}$, D. ONDRUS ${ }^{5}$ \\ ${ }^{1} 2^{\text {nd }}$ Department of Oncology, Comenius University, Faculty of Medicine, National Cancer Institute, Bratislava, Slovak Republic; ${ }^{2}$ Cancer Research \\ Institute, Slovak Academy of Sciences, Bratislava, Slovak Republic; ${ }^{3}$ Institute of Biostatistics and Analyses at the Faculty of Medicine and the \\ Faculty of Science of the Masaryk University, Brno, Czech Republic; ${ }^{4}$ Department of Surgical Oncology, Comenius University, Faculty of Medicine, \\ St. Elisabeth Cancer Institute, Bratislava, Slovak Republic; ${ }^{5} 1^{\text {st }}$ Department of Oncology, Comenius University, Faculty of Medicine, St. Elisabeth \\ Cancer Institute, Bratislava, Slovak Republic
}

${ }^{\star}$ Correspondence : martina.ondrusova@savba.sk

Received May 25, 2011 / Accepted June 22, 2011

\begin{abstract}
Breast cancer represents a major problem in oncology and epidemiology, especially because of the growing trends in its incidence, which are most pronounced in countries with historically low levels of incidence of this disease and because of the increasingly unfavorable mortality trends even in some countries where screening has been established. The purpose of this study is to analyse the incidence of breast cancer and resulting mortality in two neighbouring countries with national population-based cancer data in central Europe and to assess possible reasons for any differences discovered. The recorded increase in the incidence of breast cancer in the Slovak and Czech Republic is apparently the result of a westernizing lifestyle. In the Czech Republic the acceleration of the incidence of this disease recorded after 1991 was more pronounced than in the Slovak Republic, which may be influenced especially by the more pronounced increase in the number of mammograms but also by a higher prevalence of risk factors of the disease.

After the year 1991 a stabilization of mortality was recorded in both countries. However, this stabilization is not satisfactory but is correlated with the unsatisfactory extent (in the case of the Slovak Republic still unorganized) of screening, with the low number (or unused) mammograms, with slow onset of anti-cancer therapy and with expenditures for health care below the European average. The existing situation with an unfavourable mortality trend in all age groups indicates the importance of implementing intervention measures.
\end{abstract}

Key words: breast cancer, epidemiology, incidence, mortality, time trends

Breast cancer currently is the most frequently occurring form of cancer in women (excluding non-melanoma skin cancer), while it is an extremely rare disease in men. In 2008 the estimated number of newly diagnosed cases world-wide was $1,384,155$, which represented $22.7 \%$ share of newly diagnosed cancers among women and a standardized incidence rate was $39 / 100,000$. Breast cancer also is the most common cause of the death of females from cancer; the number of deaths in 2008 was estimated to be 458,503 with a standardized mortality rate of $12.5 / 100,000$ and $10.7 \%$ share of deaths from all types of malignant tumors in women $[1,2]$. At present, breast cancer is dominant among females in almost all countries of the world, with the exception of Bhutan, China, North Korea and Vietnam, where the estimated incidence of lung cancer incidence exceeded the number of breast cancer cases in 2008. On the other hand, the incidence of breast cancer in many developing countries is higher, respectively only slightly lower than cervical cancer and oral cavity cancers that traditionally dominate [3].

The purpose of this study is to analyse the incidence of breast cancer and the resulting mortality and to assess possible reasons for any differences discovered in two neighbouring countries in central Europe (the Slovak and the Czech Republic), both of which have national, population-based cancer registries. Despite the geographical proximity of the Slovak (SR) and Czech (CR) Republic and their common history, at present the $\mathrm{CR}$ is among the countries with a high incidence of breast cancer, while the SR ranks among the countries with an average incidence of the disease. 


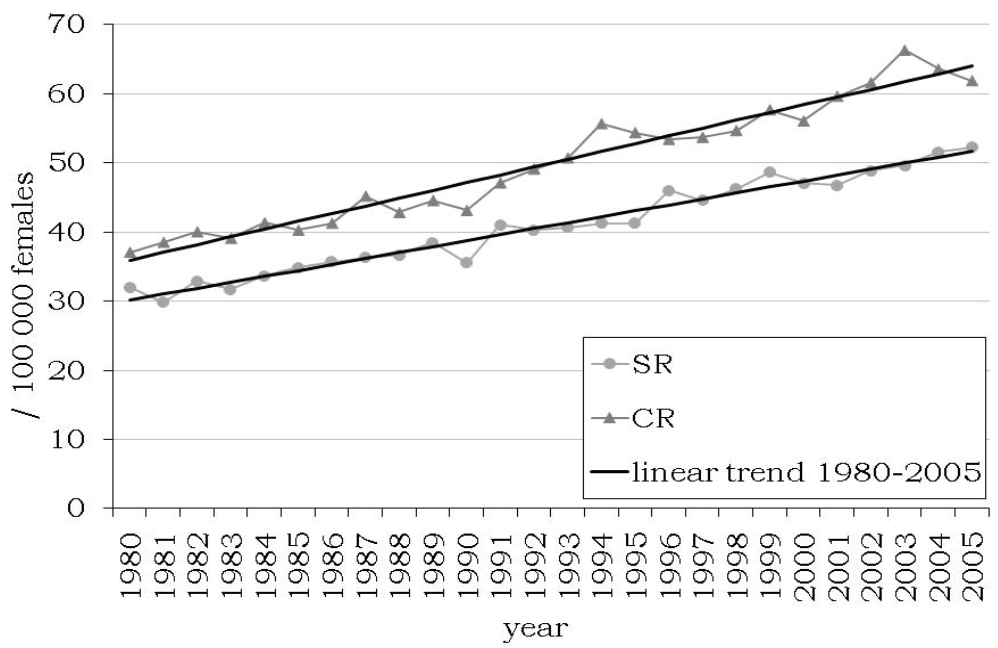

Graph 1. Trends of the standardized (to the World standard population, ASR-W) breast cancer incidence in females in the Czech (CR) and Slovak (SR) Republic

This paper compares the results detected in an analysis of the incidence of breast cancer cases and mortality in the SR and $\mathrm{CR}$, discusses possible causal factors for their incidence and differences in several descriptive indicators of the development of the disease in both countries and compares the results with selected countries in the world.

\section{Materials and methods}

The data concerning the incidence of breast cancer used in this analysis were obtained from portals of the pre-processed data of the National Cancer Registry (hereafter NCR) SR [4] (www.nor-sk.org) and the NCR CR [5] (www.svod. Cz) valid at the end of July 2009 as well as from the standard outcomes and annual reports of the NCR SR and the NCR $\mathrm{CR}$. These registries are national population-based cancer registries with high quality data [6]. The analyses of the overall incidence and mortality are based upon the period 1980-2005, for which both countries have validated data. Corresponding national mortality data were obtained from the Statistical Office of the SR and from the NCR CR. The values of incidence and mortality are presented in the form of crude rates from 2005, the last statistically closed year. A comparison with other countries is possible only after a correction of the different age structure of the population. The standardisation according to the world standard population was carried out [7] and the standardised rates (ASR-W) in the SR and CR have been compared. The trends in incidence and mortality were extracted using a separate linear regression model for each gender and country during time period 1980-2005 and then individually for the period 1980-1991 and 1991-2005. The trends are presented with a corresponding 95\% Confidence Intervals (CI) and p-value with null hypothesis being constant with time. Index of growth of ASR-W incidence was calculated using a linear regression model to the ASR-W data including the variances. The output of the regression for the slope including 95\% CI represent the index of growth. The analysis was performed using XLSTAT (www.xlstat.com) software. An increase in incidence in 1991 in both countries correlates with the introduction of high-quality imaging methods of diagnosis. Not only are the trends of incidence and mortality for the entire period of 1980-2005 compared, but the character of changes before and after the culmination of incidence in 1991 is also compared.

\section{Results}

In 2005, the number of breast cancer cases in females diagnosed in the SR was 2,198, which represents crude incidence rate of 79.3/100,000 and an ASR-W incidence of $52.2 / 100,000$ (95\% CI \pm 2.279$)$. The index of the increased standardized ASR-W incidence for 1980 was 1.75 ; from an ASR-W incidence of 29.9/100,000 (95\% CI \pm 2.043$)$ in 1980 to $52.2 / 100,000$ in 2005 . The estimated average annual increase of the ASR-W incidence for the period of 1980-2005 was 0.862 (95\% CI $=0.794$ to $0.929, \mathrm{p}<0.0001)$, annual percentage incidence growth was $2 \%$. The incidence of the disease (graph 1) in the SR had a significantly slower upward trend during the period 1980-1991, when the average annual increase of the ASR-W incidence was $0.780 / 100,000$ (95\% CI $=0.520$ to $1.040, \mathrm{p}<0.0001)$. From 1991 to 2005 , a significantly higher increase of the ASR-W incidence was recorded in the SR. The average annual increase was $0.871 / 100,000$ (95\% CI $=0.715$ to $1.026, \mathrm{p}<0.0001)$. The cumulative risk of disease calculated for the population of women between the ages 0-74 year, averaged 5.5\% during the years 2000-2005, while during the period 1980-1984 it was 


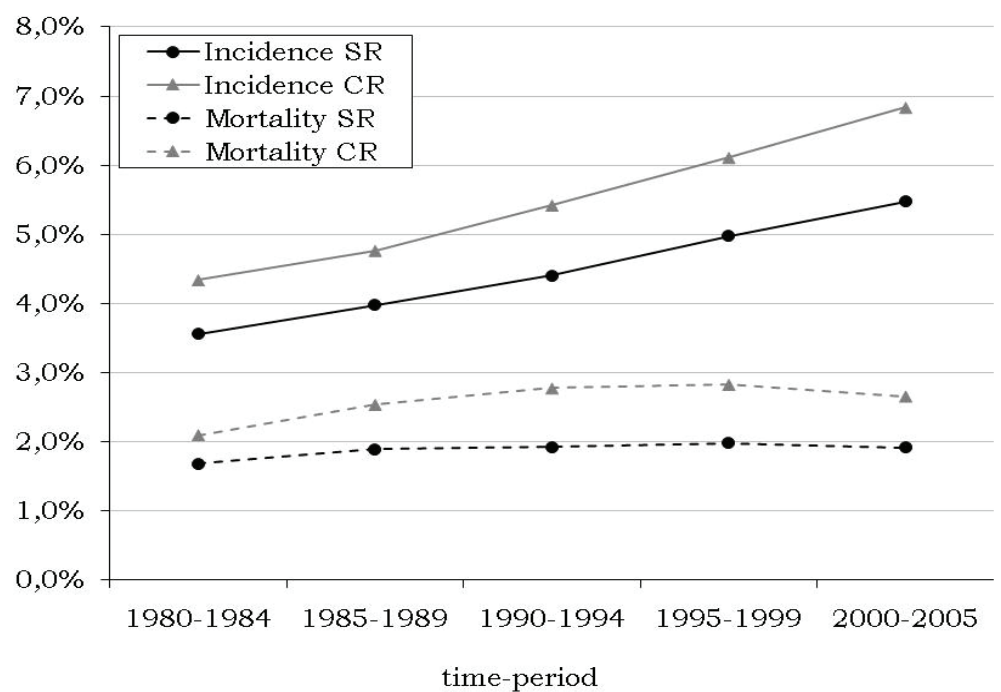

Graph 2. Cumulative risk of breast cancer disease and mortality for the population of women aged 0-74 in the Slovak (SR) and Czech (CR) Republic

only $3.6 \%$ (graph 2). The typical age of females with breast cancer in the SR during the years 1999-2003 was 50 years (25\% quantile) up to 70 years ( $75 \%$ quantile).

In the SR 707 females with breast cancer died in 2005, which represents a total mortality rate of 25.5/100,000, ASRW 15.4/100,000 (95\% CI \pm 1.204$)$. The index of the increase of ASR-W mortality was 1.02, rising from 15.1/100,000 (95\% $\mathrm{CI} \pm 1.409$ ) in 1980 to the current $15.4 / 100,000$ (however, the ASR-W mortality in the SR was $17.2 / 100,000$ in 2004). The trend in mortality expressed linearly increased gradually until its peak in 1991, when it reached the value of 19/100,000 (95\% CI \pm 2.217$)$, after which a decline was recorded. The average annual increase of ASR-W mortality during the years $1980-2005$ was $0.095 / 100,000$ ( $95 \% \mathrm{CI}=0.035$ to 0.155 , $\mathrm{p}$ $=0.003)$.

The character of the trends in ASR-W mortality (graph 3) since 1980 has changed. Mortality increased significantly until 1991, when the estimated annual average of mortality increase was $0.350 / 100,000(95 \% \mathrm{CI}=0.221$ to $0.479 \mathrm{p}=0.0001)$, the annual percentage mortality growth was $0.1 \%$. After 1991 (to $2005)$ the ASR-W mortality values stagnated, with a non-significant average annual decrease of $-0.059 / 100,000$ (95\% CI = -0.189 to $0.071 \mathrm{p}=0.345)$, the annual percentage mortality decline was $-1 \%$. The cumulative risk of death (graph 2) calculated for the age group of $0-74$ years averaged $1.9 \%$ during the years $2000-2005$. It was $1.7 \%$ at the beginning of the period analyzed (1980-1984) while the highest average of the risk of death was up to $2 \%$ during the the years 1995-1999.

In the SR a change in the percentage of breast cancer clinical stages (graph 4) has been recorded during the period 19802003. The number of cases diagnosed in the $1^{\text {st }}$ clinical stage increased significantly, and there was moderate increase in the number of cases in the $2^{\text {nd }}$ clinical stage, while a significant decrease occurred in the number of cases in the $3^{\text {rd }}$ clinical stage.
The number of cases in the $4^{\text {th }}$ clinical stage and unspecified clinical stage is relatively stable. Along with this there was, since 1993, a gradual (slow) increase in the incidence of carcinomas in situ. While in 1980 the cases diagnosed in $1^{\text {st }}$ clinical stage represented $5.9 \%$ of the total, in 2003 they already represented $25.5 \%$ of the total. In $1980,33.8 \%$ of the cases diagnosed were in the $2^{\text {nd }}$ clinical stage while by 2003 this had risen to $43.5 \%$ of the cases. In $1980,35.5 \%$ of the cases were in the $3^{\text {rd }}$ clinical stage but by 2003 they comprised only $13.6 \%$ of the cases.

In the CR, 5,630 cases of breast cancer in females were diagnosed in 2005, which represents a total incidence rate of $107.3 / 100,000$ and an ASR-W rate of 61.9/100,000 (95\% CI $\pm 1.729)$. The index of the growth of the ASR-W incidence during the analyzed period of 1980-2005 was 1.67; from the value of $37.1 / 100,000$ (95\% CI \pm 1.474$)$ in 1980 to the value of $61.9 / 100,000$ in 2005 , the last year analyzed. The average estimated annual increase of ASR-W incidence during the period $1980-2005$ was $1.124 / 100,000(95 \% \mathrm{CI}=1.018$ to 1.230 , $\mathrm{p}<0.0001)$, the annual percentage incidence growth was $2 \%$. In the course of time, the trend in the ASR-W incidence exhibited a character similar to that in the SR (graph 1).

The analysis of the period of 1980-1991 indicated a significantly slower increase of the incidence of breast cancer; the average estimated increase was $0.752 / 100,000$ (95\% CI = 0.518 to $0.986, \mathrm{p}<0.0001)$. However, after 1991 up to the last year analyzed (2005), a statistically significant acceleration of incidence was recorded, with an average annual increment of $1.133 / 100,000$ ( $95 \% \mathrm{CI}=0.865$ to $1.400, \mathrm{p}<0.0001)$. The cumulative risk of the disease in women in the age-group 0 74 years during the years 2000-2005 averaged 6.8\% while at the beginning of the period followed (1980-1984) it was $4.3 \%$ (graph 2). The typical age of women with breast cancer in the CR during 1999-2003 was 52 years (25\% percentile) up to 72 years ( $75 \%$ percentile). 


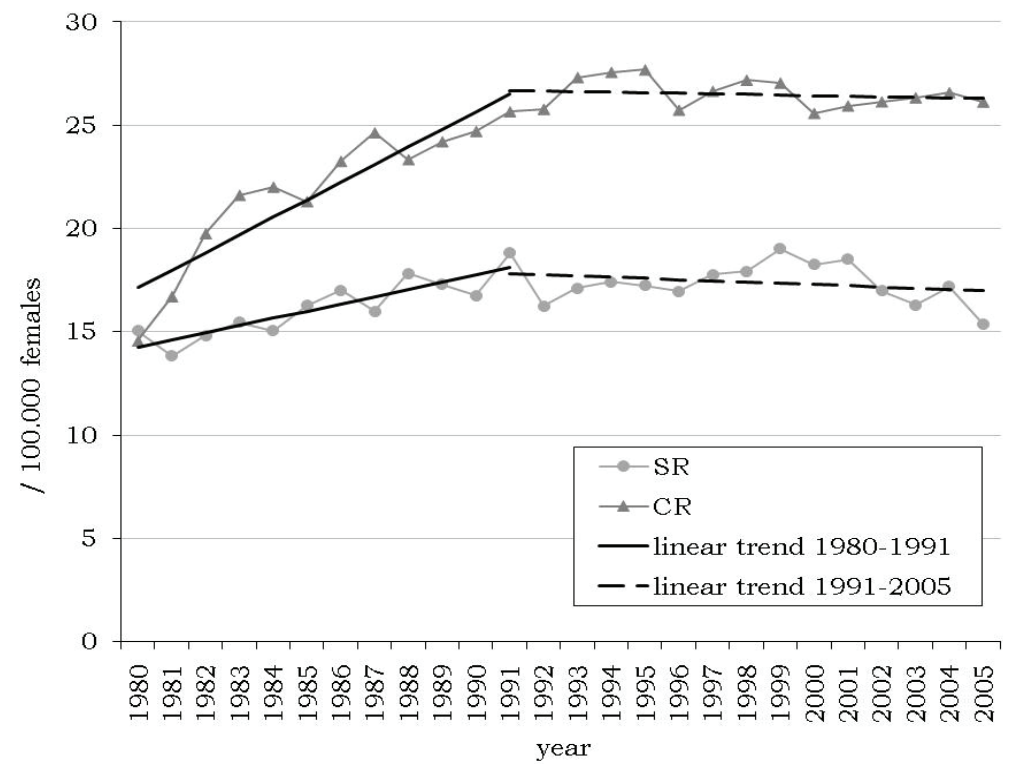

Graph 3. Trends of the standardized (to the World standard population, ASR-W) breast cancer mortality in females in the Czech (CR) and Slovak (SR) Republic

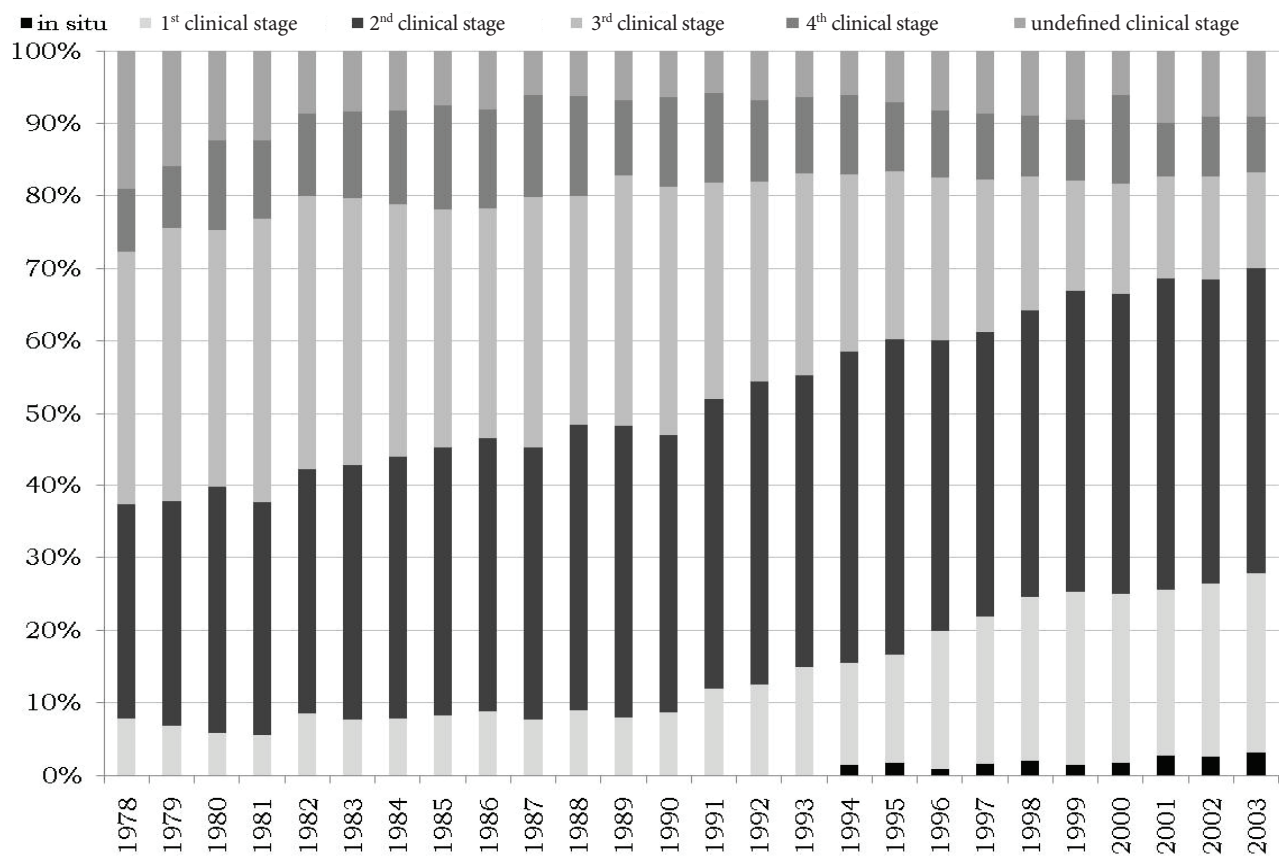

year

Graph 4. Clinical stages of breast cancer in females in the Slovak Republic (SR)

In 2005, 3,217 women died of breast cancer in the CR, which represented crude mortality rates of $61.3 / 100,000$ and an ASR-W mortality of 26.1/100,000 (95\% CI \pm 1.004 ). The index in the growth of ASR-W mortality was 1.79 , from $14.6 / 100,000(95 \% \mathrm{CI} \pm 0.883)$ in 1980 to $26.1 / 100,000$ in
2005. During the period of 1980-2005 mortality increased slightly (graph 3 ), and the expected annual average increase of ASR-W mortality was $0.345 / 100,000(95 \% \mathrm{CI}=0.235$ to $0.456, \mathrm{p}<0.0001$ ). However, the mortality rate showed a more rapid upward trend until 1991 when the average an- 


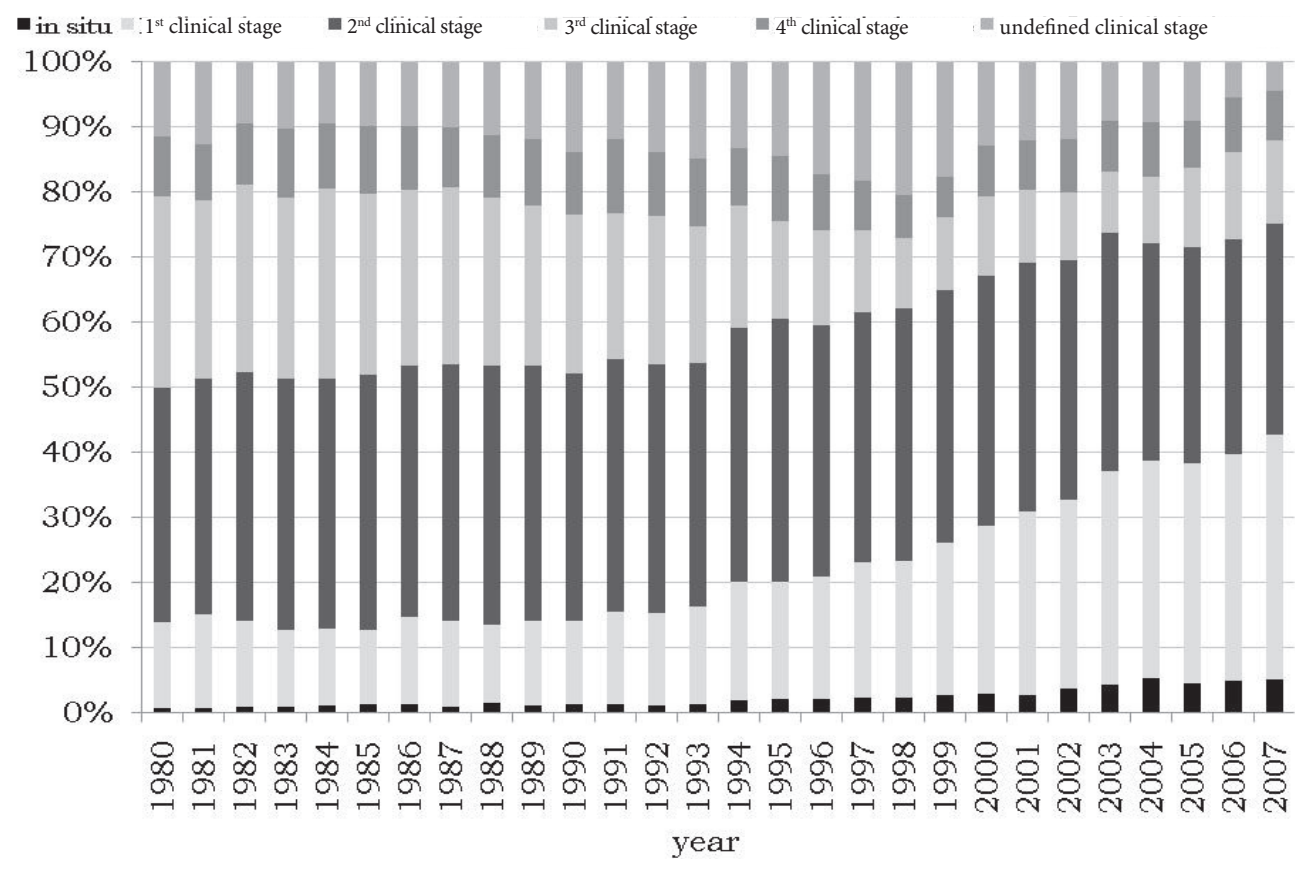

Graph 5. Clinical stages of breast cancer in females in the Czech Republic (CR)

nual increase was $0.851 / 100,000(95 \% \mathrm{CI}=0.583$ to 1.119 , $\mathrm{p}<0.0001)$, the annual percentage mortality growth was 2.4 $\%$. Thereafter the increase decelerated or, more precisely, the mortality rate stabilized (the average annual decrease from 1991-2005 was statistically insignificant $-0.027 / 100$ 000, 95\% $\mathrm{CI}=-0.122-0.068, \mathrm{p}=0.547)$, the annual percentage mortality decline was $-0.4 \%$. The cumulative risk of death in the years 2000-2005 (graph 2) in women in the age-group of 0-74 year avereged $2.7 \%$; at the beginning of the period analyzed (1980-1984) it was $2.1 \%$. The maximum risk of death $(2.8 \%)$ was during the years 1990-1994 and 1995-1999.

As in the SR, there was recorded in the CR a shift in the number of cases diagnosed in different clinical stages. A marked increase of number of cases diagnosed in the $1^{\text {st }}$ clinical stage occurred with values of $13.3 \%$ in 1980 to $34.4 \%$ in 2003 (a growth trend continued to the last year 2007 of complete statistics) and there was a significant decrease in cases in the $3^{\text {rd }}$ clinical stage (from $29.6 \%$ in 1980 to $9.9 \%$ in 2003). In contrast to the SR, in the CR there was recorded a modest increase in the number of cases in the $2^{\text {nd }}$ clinical stage (with values from $36.3 \%$ in 1980 to $38 \%$ in 2003) and a corresponding slight decrease of the number of cases in the $4^{\text {th }}$ and unspecified clinical stages. At the same time there is a more progressive increase in the CR (compared to the SR) in the number of cases of breast cancer in situ (graph 5).

\section{Discussion}

Breast cancer is a serious social and epidemiological problem often affecting women in the middle age-groups [8].
The highest estimated values of ASR-W incidence for the year 2008 are in western and northern Europe - Belgium has a dominant position (109.2/100,000), and high values are recorded also in Denmark (101/100,000), France (metropolitan 99.7/100,000), Netherlands (98.5/100,000), Ireland (93.9/ $100,000)$, Switzerland $(89.4 / 100,000)$, in the CR $(70.9 / 100,000)$ and in the USA $(76 / 100,000)$. Medium values of incidence in the range of $60 / 100,000-31 / 100,000$ in 2008 are found in Portugal $(60 / 100,000)$ and particularly in Central and Eastern Europe - in Hungary (56.8/100,000), Bulgaria (55.5/100,000), the SR (53.4/100,000), Estonia (50.2/100,000) and in Poland $(48.9 / 100,000)$. Low values in in the incidence of disease under $30 / 100,000$ are attained in the majority of African countries, some Asian countries (China, India) and some South American countries [9]. In general, high curves in the breast cancer incidence are in developed countries due to westernizing lifestyle and a higher prevalence of known risk factors for the disease, many of which - e. g. early start menarche, nulliparity, late age at the time of first childbirth, late age at any birth, low parity, exogenous hormone exposure (especially oral contraceptives and hormon-replacement therapy, HRT), obesity and late menopause - are related to the hormonal (estrogen) environment, to which the breast is exposed from menarche until the end of ovulation at menopause [1].

The development in the incidence of breast cancer manifests an upward trend in almost all countries of the world. The highest increase in the incidence values is observed in populations with historically low levels, often in developing countries. A significant increase in the incidence of the disease was observed in several European countries during the 1990s. 
These upward trends are highest among women over 50 years of age, which indicates that the introduction of mammography is probably a main cause for the increase $[1,10]$. The highest increase in incidence was observed in the countries of Central and Eastern Europe.

An acceleration in the increase of the breast cancer incidence after 1991 was observed in the SR as well as in the CR, from the average annual increase of the ASR-W incidence of $0.78 / 100,000$ recorded in the SR in $1980-1991$ to $0.871 / 100,000$ for the years 1991-2005 and in the case of the CR from 0.752/ 100,000 in $1980-1991$ it increased to $1.133 / 100,000$ during the years 1991-2005. The increase in the values of incidence is influenced, on the one hand, by a rapid increase in the number of mammographic examinations since 1990-ties, which have a growing trend in both countries $[11,12]$ and from the perspective of the discovered differences are probably performed more extensively in the CR than in the SR. On the other hand, the real increase of numbers of cases is affected by the higher prevalence of risk factors in these countries, for example an increase in the use of HRT (official development indicators of use of HRT in the SR and CR are not available). Deviations in the development of long-term trends in the increase incidence were observed only recently in some, mainly Western countries. A decrease in the values of the incidence of the disease from the beginning of the millennium in selected countries (e. g. USA, UK, France and Austria) has been associated with a significant reduction in the combined application of postmenopausal HRT in these countries [13]. On the other hand, the decrease in the incidence of breast cancer (due to drop in the use of HRT) in non-Hispanic white women in the USA did not continue after 2003 [14]. Possible explanations might consist in an insufficient absolute decrease in HRT use after 2003, or an improved sensitivity of mammography without the influence of HRT [14].

The highest value of the standardized ASR-W mortality was reached in the estimates for 2008 in Barbados (29.2/100,000), followed by Lebanon, Armenia, Jordan, Belgium and Denmark. The SR was in the $65^{\text {th }}$ place with ASR-W mortality levels of $15.1 / 100,000$ and the CR ranked $79^{\text {th }}(14.5 / 100,000)$. The lowest levels of mortality are reported in many East Asian countries [9]. In several high-risk countries the mortality curves are characterized by a decline due to a combination of mammographic screening, and intensification of diagnosis of the disease in early clinical stages, by which a larger number of small tumors were found and finally by an improvement of the primary and adjuvant therapy of the disease [1].

Over the long term, the development of mortality differs between countries. During the years 1950-1980 an increase in mortality values was recorded in most European countries, particularly in Southern and Eastern Europe. A decrease of the mortality values in Great Britain was observed already at the beginning of the 1990s and this trend can now be observed in some other European countries $[1,15]$. In the SR and CR after an increase in the average annual values of the ASR-W mortality over the years 1980-1991 (the increase was greater in the
CR than in the SR), the values stabilized (1991-present), which correlates with the higher use of mammography examination after 1991 and a concurrent increase in the number of cases caught in the initial clinical stage. However, the stagnation in overall mortality after 1991 is not sufficient (its decline was expected) and according to Autier et al. [16] this correlates with a low, non-organized screening, a low number (or nonuse) of mammograms, the slow onset of anti-cancer therapy and with the fact that the funding of health care is below the European average. Secondly, the stagnation or slow decline of mortality is influenced by rapid changes in these countries after the collapse of the communist regime in the 1990s, such as the raising of the age of the first birth etc. Persistent situation with rising rates of mortality in all age groups in eastern European countries indicates the importance of introducing intervention measures [17].

Different trends of mortality in European countries can be explained by several factors. The mammographic screening of women (50-69 years old) is effective in terms of reducing mortality of breast cancer [18], while the decline of mortality trends reflects an increasing number of mammograms performed in developed countries (including the SR and CR). One of the indirect positive effects of mammography is the disease transfer to lower, prognostically more favorable clinical stages and better organization of diagnostic management, as a result of awareness and preventive measures $[1,19]$. In the SR and CR during the period 1980-2003 the most frequently diagnosed was the $1^{\text {st }}$ clinical stage of younger (0-34 years) as well as elderly (over 35 years) women. However with an increase in age the number of cases in the higher clinical stages with less favorable prognoses, rose. The undefined clinical stage predominated in patients of the most advanced age group (over 70 years). During the course of 25 years a significant increase in number of breast cancer cases in the $1^{\text {st }}$ and $2^{\text {nd }}$ clinical stage was recorded in the SR and CR, and there was likewise an increase (although less progressive) recorded in carcinomas in situ. The reduction of mortality values in countries without screening programs, or before the introduction of screening, is ascribed to several improvements in the management of the therapy of the disease, including the introduction of therapy protocols, improved adjuvant therapy, chemotherapy and hormonal therapy and better therapeutic ,guidelines. Mathematical modeling of data from the USA suggests that both methods - screening and adjuvant therapy - almost equally contributed to the significant reduction of mortality observed in the period 1975-2000 [20].

An early age of menarche (before the age of 12) is associated with an increased risk of premenopausal and postmenopausal breast cancer [21, 22]. The protective effect of menarche at a late age was statistically of greater significance for ER (estrogen-receptors)+/PR (progesteron-receptors)+ than ER/PR- subtypes of cancer in the meta-analysis of Ma et al. [23]. Shorter menstrual cycles are also associated with an increased risk of breast cancer, due to more frequent lutheal phases of the cycle with high levels of estrogen, progesterone and prolifera- 
tive activity in the mammary gland [21,24]. A woman's age at the time of menopause affects the length of estrogen exposure to the organism. Generally the risk of breast cancer increases by approx. $3 \%$ of each year of a delayed menopause. The effect of artificial menopause (e. g. after bilateral oophorectomy) is stronger (due to a sudden termination of ovarian function) than the onset of natural menopause (with the slow reduction of ovarian function) [21].

Nulliparas also have an increased risk of postmenopausal breast cancer compared with women who have given birth $[25,26]$. According to the overview of Ma et al. [23] each birth reduces the risk of $\mathrm{ER}+/ \mathrm{PR}+$ cancer by $11 \%(\mathrm{RR}$ per birth $=$ $0.89,95 \% \mathrm{CI}=0.84-0.94)$. Women of an older age at first birth have a greater risk for $\mathrm{ER}+/ \mathrm{PR}+$ breast cancer than women in the younger age category, but age at first birth is not associated with the risk of ER-/PR- cancer [23]. Breast-feeding and its duration directly affect the level of estrogen in the body and the overall risk of both ER+/PR+ and ER-/PR- subtypes of cancer decreases with prolonging the time of lactation. Taking oral contraceptives may increase the risk of breast cancer because they contain a combination of estrogen and progestin, which may be higher than the physiological levels produced during the menstrual cycle. A significant increase in the use of hormonal contraception in the SR and CR was recorded since 1991; previously their use was long-term stabilized at very low levels. In 2005, 19.5\% of women (aged $15-49$ ) in the SR were taking a hormonal contraception (by 2008 this number had increased to $22.3 \%$ and to $40 \%$ in the CR) while in 1996 it was only 7.75\% [23, 27-30]. Despite the fact that the increasing incidence of the disease corresponds with the increased use of hormonal contraceptive (in the CR more than in the SR), for cases of the development of breast cancer, the age and length of time women used contraception is fundamental [25], although this data for the SR and CR are lacking. With the use of HRT at menopause the risk of breast cancer among current, respectively recent and longterm users is increased; after discontinuing HRT the risk subsides [21, 31-34].

According to the results of a randomized study concerning the evaluation of the risks and benefits of the use of estrogen and progestagen preparations by healthy postmenopausal women, the risk of disease increases by $26 \%$, which agrees with results of further studies that evaluated the risk higher by $15 \%$ when taking combined HRT for less than 5 years in comparison with a 53\% increased risk among women using combined HRT for more than 5 years [35]. Official data on the use of HRT for the CR and SR are not available. Among the environmental factors that increased the risk of breast cancer can be included smoking, especially during adolescence when the breast is most sensitive to the effects of carcinogens [21], although the clear risk of active or passive smoking has not been demonstrated in the prospective studies [36].

Compared with nationwide figures, Bencko et al. [37] found a lower incidence of disease in the Michalovce district (eastern part of the SR), where during the years $1959-1983$ a higher exposure to polychlorinated biphenyl (which may have anti-estrogen or androgen effect) has been shown. Despite popular reports of an increased risk in the use of underarm antiperspirants, the studies have not shown a clear effect [38]. Similarly silicone implants do not increase the risk of breast cancer [21]. Some studies [39] have shown an increased risk in premenopausal (RR 1.42) and postmenopausal (RR 1.28) women who are taller $(175 \mathrm{~cm}$ or more compared with a group of $160 \mathrm{~cm}$ and less), which is probably related to the higher energy intake in childhood.

Obesity in postmenopausal women contributes to an increased risk of breast cancer by influencing estrogen metabolism, while obesity in pre-menopausal period slightly reduces the risk [21, 40]. According to the conclusions of IARC WHO [41] physical activity reduces the risk of breast cancer by inhibiting the production of steroid hormones in the ovaries, by reducing insulin production, weight reduction and the production of IGFPB- $1^{\text {st }}$. Genetically determined breast cancer is about $5-10 \%$ of all cases, the most common is the BRCA 1 gene mutation located on the long arm of the $17^{\text {th }}$ chromosome ( $52 \%$ genetically related tumors), and the BRCA-2 located on the long arm $13^{\text {th }}$ chromosome (32\%) and $16 \%$ are mutations of other genes.

For the Li-Fraumeni syndrome the cause is a mutation of a tumor-suppressor gene p53 that is reflected in an increased risk of several malignancies, including breast cancer. Mutations in the BRCA 1 gene is a cummulative risk of $90 \%$ for those up to the age of 80 , while for mutations in BRCA 2 the risk is $24 \%$ (there also exists an increased risk of ovarian cancer). Inherited forms of cancer are usually diagnosed at a younger age (before 65 years of age, often in pre-menopause) and disabled women are at high risk of recurrence [42, 43]. An increased risk of breast cancer has been observed in women who in childhood were under the influence of ionizing radiation (e. g. during the World War II). The irradiation of the breast in the period of its development not only can result in hypoplasia but also an increased risk of carcinogenesis at a later age. For example, these are women who in childhood (in accordance with the existing state of knowledge) were irradiated for benign disorders (e. g. hemangiomas), or who in childhood suffered from other malignant tumors and whose mammary glands were located in the irradiation zone. The effect of repeated mammographic examinations on an increase in the risk of carcinogenesis in women over 50 years is balanced by a reduction in the mortality of women caused by breast cancer that was diagnosed due to this screening $[13,44]$.

Despite the observed marked increase in the values of incidence of the disease in the SR and CR after the introduction of high-quality diagnostic imaging methods and in the coincidence of an increase of the number of cases in prognostically favorable clinical stages only a stabilization and not a decrease in mortality has manifested itself in recent years. The prevailing situation indicates the importance of introducing intervention measures (nationwide disease screening) in the case of the SR, supported also by legislation that would result in an increased 
detection of tumors in lower clinical stages and could improve the survival ability of the patients.

\section{References}

[1] FERLAY J, HER C, AUTIER P, SANKARANARAYANAN R Global burden of Breast Cancer. In: Breast cancer epidemiology, Springer Sciences+Business Media, LLC, 2010.

[2] JEMAL A, BRAY F, CENTER M, FERLAY J, WARD E et al. Global cancer statistics. Ca Cancer J Clin 2011; 61: 69-90. http://dx.doi.org/10.3322/caac. 20107

[3] CURADO MP, EDWARDS B, SHIN HR, STORM H, FERLAY $\mathrm{J}$ et al (eds.) Cancer Incidence in Five Continents, Vol. IX, IARC Scient. Publ. No. 160, IARC, Lyon 2007.

[4] ONDRUSOVA M, PLESKO I, SAFAEI-DIBA CH, OBSITNIKOVA A, STEFANAKOVA D et al. Comprehensive analysis of incidence and mortality of malignant tumours in the Slovak Republic [online]. National Cancer Registry of the Slovak Republic, NHIC, Bratislava 2007. http://www.nor-sk.org/.

[5] DUSEK L, MUZIK J, KUBASEK M, KOPTIKOVA J, ZALOUDIK J et al. Epidemiology of malignant tumours in the Czech Republic [online]. Masaryk University, Czech Republic, Bratislava 2005. http://www.svod.cz.

[6] AARELEID T Central and Eastern Europe, pp. 19-20. In: Whelan S. L.: IARC Newsletter No. 33 - Dec, Lyon 2003. www. iarc.com.fr

[7] BRAY F, GUILLOUX A, SANKILA R, PARKIN DM Practical implications of imposing a new world standard population. Cancer Causes Control 2002; 13:175-182. http://dx.doi. org/10.1023/A:1014344519276

[8] BOYLE P, FERLAY J Cancer incidence and mortality in Europe, 2004. Ann Oncol 2005; 16: 481-488. http://dx.doi. org/10.1093/annonc/mdi098

[9] FERLAY J, SHIN HR, BRAY F, FORMAN D, MATHERS C et al. GLOBOCAN 2008, Cancer Incidence and Mortality Worldwide: IARC CancerBase No. 10 [Internet]. IARC, Lyon 2010. Available from: http://globocan.iarc.fr/

[10] DUSEK L, MUZIK J, GELNAROVA E, FINEK J, VYZULA R et al. Cancer incidence and mortality in the Czech Republic. Klin Onkol 2010; 23: 311-324.

[11] MAJEK O, DANES J, ZAVORAL M, DVORAK V, SUCHANEK $S$ et al. Czech national cancer screeening programmes in 2010. Klin Onkol 2010; 23: 343-353.

[12] SKOVAJSOVA M Breast cancer screening in the Czech Republic: results from mammographic screening centers 2003-2209 (in Czech). Onkologie 2011; 5: 9-15 (in Czech).

[13] ABRAHAMOVA J Breast cancer - epidemiology, risk factors, pp. 11-18. In: Abrahamova J, Povysil C, Horak J. et al (eds.) Atlas of breast cancer, Grada Publ., Praha 2000. (in Czech).

[14] DESANTIS C, HOWLADER N, CRONIN KA, JEMAL A Breast cancer incidence rates in U.S.women are no longer declining. Cancer Epidemiol Biomarkers Prev 2011; 20: 733739. http://dx.doi.org/10.1158/1055-9965.EPI-11-0061

[15] BOTHA JL, BRAY F, SANKILA R, PARKIN DM Breast cancer incidence and mortality trends in 16 European countries. Eur J Cancer 2003; 39: 1718-29. http://dx.doi.org/10.1016/S09598049(03)00118-7
[16] AUTIER P, BONIOL M, LA VECCHIA C, VATTEN L, GAVIN A et al. Disparities in breast cancer mortality trends between 30 European countries: retrospective trend analysis of WHO mortality database. BMJ 2010 Aug 11;341:c3620. doi: 10.1136/ bmj.c3620. http://dx.doi.org/10.1136/bmj.c3620

[17] LEVI F, LUCCHINI F, NEGRI E, LA VECCHIA C The fall in breast cancer mortality in Europe. Eur J Cancer 2001; 37: 1409-1412. http://dx.doi.org/10.1016/S0959-8049(01)00144Z

[18] IARC working group on the Evaluation of Cancer Preventive Strategies. Breast cancer screening. IARC Handbooks of Cancer Prevention, Vol. 7, IARC Press, Lyon 2002.

[19] VAN SCHOOR G, MOSS SM, OTTEN JDM, DONDERS R, PAAP E et al. Increasingly strong reduction in breast cancer mortality due to screening. Br J Cancer 2011; 104: 910-914. http://dx.doi.org/10.1038/bjc.2011.44

[20] BERRY DA, CRONIN KA, PLEVRITIS SK, FRYBACK DG, CLARKE $L$ et al. Effect of screening and adjuvant therapy on mortality from breast cancer. N Engl J Med 2005; 353: 17841792. http://dx.doi.org/10.1056/NEJMoa050518

[21] COLDITZ GA, BAER HJ, TAMINI RM Breast Cancer, Chapter 51, pp. 995-1012. In: Schottenfeld D, Fraumeni JF (eds.) Cancer Epidemiology and Prevention. Oxford University Press, New York 2006.

[22] SVOBODNIK A, ABRAHAMOVA J, KUBALA E, DUSEK L, FORETOVA L et al. Prediction of origin risk of breast cancer in women in the Czech Republic - methodology of the data collection for validation of the mathematic predictive model Klin Onkol 2001; 14: 135-141. (in Czech).

[23] MA H, BERNSTEIN L, PIKE MC, URSIN G Reproductive factors and breast cancer risk according to joint estrogen and progesterone receptor status: a meta-analysis of epidemiological studies. Breast Cancer Res 2006; 8: R43. http://dx.doi. org/10.1186/bcr 1525

[24] MCCORMACK VA, BOFFETTA P Today's lifestyles, tomorrow's cancers: trends in lifestyle risk factors for cancer in low- and middle-income countries. Ann Oncol 2011 (in press).

[25] BELLA V Risk factors, Chapt. 3, p 21-27 In: Bella V et al (ed.) Breast Cancer. Advert Ltd., Banska Bystrica 2005. (in Slovak).

[26] PORTER P L Global trends in breast cancer incidence and mortality. Salud Publica Mex 2009; 51: (Suppl.) 141-146. http://dx.doi.org/10.1590/S0036-36342009000800003

[27] Composite authors: Medical Yearbook of the Slovak Republic 1996 IHIS, Bratislava 1999. (in Slovak).

[28] Composite authors: Medical Yearbook of the Slovak Republic 2005 NHIC, Bratislava 2006, (in Slovak).

[29] Composite authors: Medical Yearbook of the slovak Republic 2008 NHIC, Bratislava 2009, (in Slovak).

[30] FANTA M News in the hormonal contraception. Lekarske listy (attachment ZdN), 2009, No. 9, pp. 26-28. (in Czech).

[31] RENARD F, VANKRUNKELSVEN P, VAN EYCKEN L, HENAU K, BONIOL $M$ et al. Decline in breast cancer incidence in the Flemish region of Belgium after a decline in hormonal replacement therapy. Ann Oncol 2010; 21: 23562360. http://dx.doi.org/10.1093/annonc/mdq240 
[32] BANKS E, CANFELL K Recent declines in breast cancer incidence: mounting evidence that reduced use of menopausal hormones is largely responsible. Breast Cancer Res 2010; 12: 103. http://dx.doi.org/10.1186/bcr2463

[33] VERKOOIJEN HM, BOUCHARDY C, VINH-HUNG V, RAPITI E, HARTMAN $M$ The incidence of breast cancer and changes in the use of hormone replacement therapy: A review of the evidence. Maturitas 2009; 84: 80-85.

[34] VON EULER-CHELPIN M Breast cancer incidence and use of hormone therapy in Denmark 1978-2007. Cancer Causes Control 2011; 22: 181-187. http://dx.doi.org/10.1007/s10552$\underline{010-9685-4}$

[35] ROSSOUW JE, ANDERSON CL (eds.) Risks and benefits of estrogen plus progestin in healthy post menopausal women: principal results from the WHI randomized controlled trial. JAMA 2002; 288: 321-333. http://dx.doi.org/10.1001/ jama.288.3.321

[36] EGAN KM, STAMPFER MJ, HUNTER D, HANKINSON $\mathrm{S}$, ROSNER BA et al. Active and passive smoking in breast cancer. Prospective results from the Nurses'health study. Epidemiology 2002; 13: 138-145. http://dx.doi.org/10.1097/ 00001648-200203000-00007

[37] BENCKO V, RAMES J, ONDRUSOVA M, PLESKO I, JURICKOVA L et al. Human exposure to polyhalogenated hydrocarbons and incidence of selected malignancies - central European experience. Neoplasma 2009; 56: 353-356. http:// dx.doi.org/10.4149/neo $2009 \quad 04 \quad 353$
[38] MIRICK DK, DAVIS S, THOMAS DB Antiperspirant use and the risk of breast cancer. J Natl Cancer Inst 2002; 94: 15781580.

[39] VAN DEN BRANDT PA, SPIEGELMAN D, YAUN SS, ADAMI H-O, BEESON L et al. Pooled analysis of prospective cohort studies on height, weight and breast cancer risk. Am J Epidemiol 2000; 152: 514-527. http://dx.doi.org/10.1093/ aje/152.6.514

[40] LACEY JV, KREIMER AR, BUYS SS, MARCUS PM, CHANG $S-C$ et al. Breast cancer epidemiology according to recognized breast cancer risk factors in the Prostate, Lung, Colorectal and Ovarian (PLCO) Cancer Screening Trial Cohort. BMC Cancer 2009; 9: 84

[41] IARC: Weight control and physical activity. IARC Handbooks on Cancer Prevention. Vol. 6, IARC Press, Lyon 2002, 327 pp.

[42] VYZULA R, NEUMANOVA R, SKOVAJSOVA R Breast Cancer Chapt. 20, pp. 195-211. In: Adam Z, Vorlicek J, Vanicek J et al (eds.) Diagnostic and therapuetic procedures for malignant diseases. Grada Publ., Praha 2002 (in Czech).

[43] PETRUZELKA L Malignant lung tumors, pleura and mediastinum Chapt. 4, pp. 128-140. In: Petruzelka L, Konopasek B (eds.) Clinical Oncology, Publ. Karolinum, Praha 2003 (in Czech).

[44] ALTANER C Molecular causes of breast tumors Chapt. 2, pp. 15-20. In: Bella V et al (ed.) Breast cancer. Advert Ltd., Banska Bystrica 2005. (in Slovak). 